Int. J. Dev. Biol. 51: 739-743 (2007)

doi: $10.1387 / \mathrm{ijdb} .062198 \mathrm{ar}$

Short Communication

\title{
Human conjunctival epithelial precursor cells and their progeny in 3D organotypic culture
}

\author{
ALFREDO ROSELLINI ${ }^{1}$, SANDRA PAPINI ${ }^{1}$, CLAUDIO GIANNARINI ${ }^{2}$, MARCO NARDI ${ }^{3}$ \\ and ROBERTO P. REVOLTELLA ${ }^{1, *}$ \\ ${ }^{1}$ Foundation O.N.L.U.S. "Stem Cells and Life", Pisa and Institute of Biomedical Technologies, C.N.R., Pisa, \\ ${ }^{2}$ Corneal Tissue and Cell Bank of Tuscany, Center "P. Perelli" ASL2, Hospital of Lucca, Lucca and \\ ${ }^{3}$ Department of Neuroscience, Section of Ophthalmology, University of Pisa, Pisa, Italy
}

\begin{abstract}
We report on an in vitro organ culture method to investigate human conjunctival epithelial basal precursor cells and their progeny within a more natural three-dimensional microenvironment. Conjunctival fragments were cultured on gelatin sponges in medium with $10 \%$ FBS. The conjunctival phenotype of the epithelium was confirmed by the expression and distribution of a panel of markers (p63, CK-13/CK-10, CK-19, Ki-67, PAS for goblet cells, CD45 for infiltrating interlamellar leukocytes and nestin for mesenchymal and ocular epithelial precursor cells). After 7 days, the epithelium had exfoliated its superficial layers (mostly CK-19 positive cells and all goblets), maintaining only 1-2 layers of basal/parabasal cells, p63, CK-13/CK-10 and nestin positive cells, firmly attached to the specimen. After 14 days, a new multilayered epithelium was formed, consisting of p63, CK-13/CK-10, nestin positive cells and in the high-zone CK-19 positive cells with new goblets. Additionally, we found interlamellar leukocytes which had probably migrated from capillaries that continued to be well maintained in the subepithelial stroma. Cells dispersed from conjunctival epithelium and co-cultured with feeder post-mitotic NIH3T3 fibroblasts formed mosaics displaying a basal epithelial phenotype. These cells expressed CD133 as revealed by RT-PCR. These organ cultures provide new opportunities to investigate epithelial reconstitution of the conjunctival surface and changes that may have occurred to their stem/ precursor cells during adaptation to varying conditions in vitro.
\end{abstract}

KEY WORDS: epithelial basal precursor, stem cell, niche, epithelium regeneration, interlamellar leukocytes

The conjunctival epithelium is a stratified, non-keratinized epithelium containing goblet epithelial cells. It can be distinguished by the corneal epithelium by the expression of different cytokeratins, mucins and by the presence of glycocalix (Meller et al., 2002). In the human conjunctiva, goblet cells secreting gel-forming mucins, can occur singly or in greater numbers lining epithelial infoldings or crypts (Shatos et al., 2003). Decrease or loss of mucin/ glycocalix production (Paladino et al., 2004; Pflugfelder et al., 1997) generate squamous metaplasia, which may lead to dry eye and ocular surface diseases. In the conjunctiva, putative epithelial stem cells are concentrated mainly in the fornix region, but can be found also along the whole inner epithelium layer (Lavker et al., 1998). Conjunctival epithelial precursor cells are bipotent cells giving rise to either goblet and non-goblet keratinocytes and good candidate to be conjunctival stem/precursor cells (Wei et al., 1997; Pellegrini et al., 1999). Conjunctival epithelial stem/precursor cells can be maintained and expanded ex vivo, if cultivated upon appropriate matrix components, on which both goblet and non-goblet keratinocytes could be expanded (Santos et al., 2005; Connon et al., 2006).

Intact small fragments of conjunctiva were cultivated in an appropriate medium and analysed at different time intervals [prior to culture (T0), after 7 days (T1) and 14 days(T2)] for histology and for the expression of different cellular markers.

\section{D-organotypic cultures on sponges}

Conjunctival fragments on gelatin-supports, revealed good maintenance of 3D-tissue-architecture and cellular heterogeneity throughout the whole period of cultures. At each time in culture, the stromal compartment appeared well maintained, with few capillaries that remained apparently intact and remarkably un-

Abbreviations used in this paper: 3D, three dimensional; RT-PCR, reverse transcriptase- polymerase chain reaction.

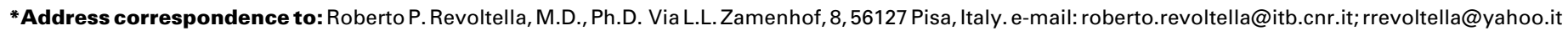



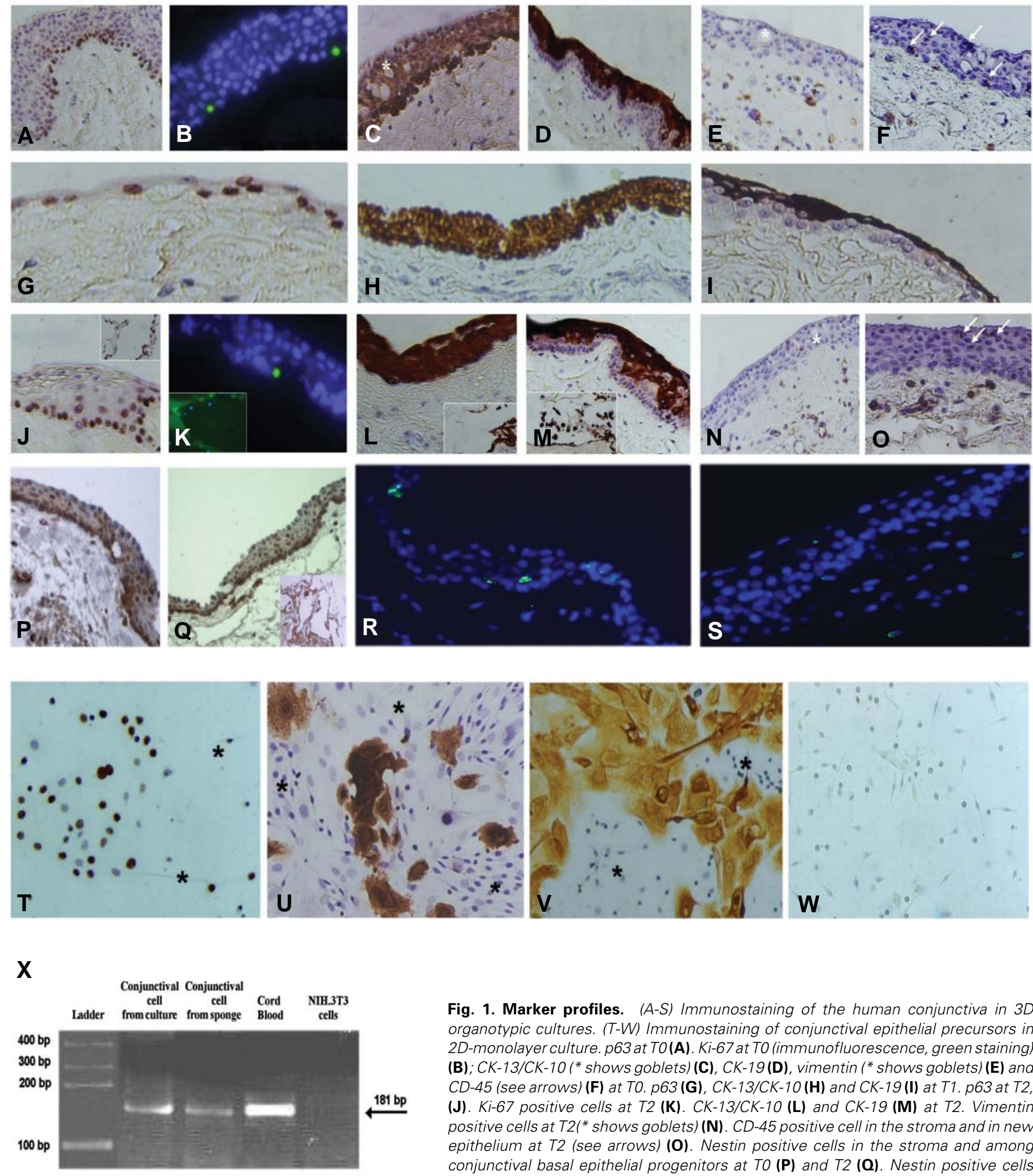

Fig. 1. Marker profiles. (A-S) Immunostaining of the human conjunctiva in $3 D$ organotypic cultures. (T-W) Immunostaining of conjunctival epithelial precursors in 2D-monolayer culture. p63 at TO(A). Ki-67 at TO (immunofluorescence, green staining) (B); CK-13/CK-10 ${ }^{*}$ shows goblets) (C), CK-19 (D), vimentin (* shows goblets) (E) and CD-45 (see arrows) (F) at T0. p63 (G), CK-13/CK-10 (H) and CK-19 (I) at T1. p63 at T2, (J). Ki-67 positive cells at T2 (K). CK-13/CK-10 (L) and CK-19 (M) at T2. Vimentin positive cells at T2(* shows goblets) (N). CD-45 positive cell in the stroma and in new epithelium at T2 (see arrows) (0). Nestin positive cells in the stroma and among conjunctival basal epithelial progenitors at T0 (P) and T2 (Q). Nestin positive cells migrated into the sponge (insert $\mathbf{Q})$. Apoptotic cells $(<1 \%)$ were equally detected at TO (R) and at T2 (S) in culture. Epithelial cells infiltrating the underlying sponge are shown in the insets of images (J,K,LM and $\mathbf{Q})$. Epithelial cells isolated from fresh conjunctival fragments after trypsin incubation, were pipetted on a monolayer of mit-c treated murine NIH.3T3 fibroblasts as a source of feeder layer $(*)$. Colonies were positive for 063 (T), CK-13/CK-10 (U), CK-19 (V) but nor for CK-3 (W). (For all figures original magnification, $400 X)$. RTPCR analysis of CD133 mRNA (X). Positive control: human cord blood; negative control: murine NIH3T3 cells. 
changed throughout the experiment.

\section{TO}

p63 expression (Fig. 1A) was exclusively confined to the nucleus of cells of the basal layer of the conjunctiva. $5 \% \pm 2.2 \%$ of basal epithelial cells were cycling, (positive immunostaining for Ki-67, Fig. 1B). CK-13/CK-10 were detected on the whole conjunctival epithelium, highly expressed in the cytoplasm of basal/ parabasal cells and gradually less in the upper layers (Fig. 1C). In contrast, CK-19 was never expressed in the basal/parabasal layers (Fig. 1D). CK-3 was never detected in the conjunctival epithelium (not shown). A small number of scattered goblet cells was detected in the more superficial epithelial layers of the epithelium (asterisk, Fig. 1C). Vimentin was expressed in endothelial and dispersed subepithelial stromal cells (Fig. 1E) and CD45 within the stroma in interlamellar monocyte/dendritic-like cells infiltrating the epithelium (Fig. 1F). Nestin was detected in the basal/parabasal layer of the epithelium (Fig. 1P). CD117 was never expressed at any culture time (not shown).

\section{T1}

The most superficial epithelial cell layers had detached, while the remaining epithelium was reduced to a mono/bi-layer. Epithelial precursor cells which had remained, selectively expressed p63 and CK-13/CK-10 (Figs. $1 \mathrm{G}$ and $1 \mathrm{H}$ ). Basal cells never expressed CK-19 (Fig. 1I). Cycling cells $\left(\mathrm{Ki}-67^{+}\right)$were $15 \% \pm 3 \%$ of these cells in the explants.

\section{T2}

Conjunctival epithelium appeared to have reconstituted a nonkeratinized squamous epithelium (3-5 layers) lining over the whole external surface of the fragment. Basal/parabasal layers contained a prominence of p63 positive cells (Fig. 1J) with a proportion of $10 \% \pm 1.25 \%$ cycling cells $\left(\mathrm{Ki}-67^{+}\right)$(Fig. $\left.1 \mathrm{~K}\right)$. The cells of the new epithelium expressed CK-13/CK-10 (Fig. 1L) with only a small proportion of more superficial cells expressing CK-19 (Fig. 1M). A very small number of goblet cells $(<1 \%)$ was also detected in the more superficial epithelial layers of the new epithelium. This new epithelium showed the tendency of infiltrating into the underlying sponge with cells that were stained for p63 and both CK-13/CK-10 and CK-19 (see inserts of Fig. 1J, Fig. 1L and Fig. $1 \mathrm{M}$ ). Vimentin and CD45 positive cells were present within small capillary structures and dispersed within the conjunctival stroma. The presence of a small fraction of interlamellar leukocytes phenotypically resembling monocyte/dendritic-like cells was detected infiltrating the new epithelium (Fig. $1 \mathrm{~N}$ and Fig. 1O).

Nestin-staining remained positive in the basal and parabasal layers of the epithelium.

In the sponge approximately $70 \%$ of cells expressed nestin. In addition, both at T0 and at T2, in the stroma several mesenchymal-like cells were positive for nestin immunoreactivity (Fig.1 P and Fig 1Q).

At T0d, as well as at T1 (not shown) and T2, a limited fraction of apoptotic cells was equally detected $(<1 \%)$ (Fig. 1R and Fig. 1S respectively), within the epithelium and the stroma, demonstrating that the conjunctival epithelium and stromal elements were well preserved in vivo as well as in prolonged 3D-organotypic culture

\section{Isolation and expansion of epithelial basal stem/precur- sor cells in co-culture with murine NIH.3T3 fibroblasts as a feeder layer}

Only a small fraction of epithelial cells isolated directly from the conjunctival explant by enzymatic digestion $(<0.1 \%$ of the cells) became adherent and could initiate colonies, forming mosaics of enlarging clusters of tightly adherent polygonal cells. After each passage only a limited proportion of adherent cells (about 1\%) formed enlarging colonies with high self-replication efficiency. These cells could be further sub-cultivated by division at subconfluence for at least 2-4 passages. The presence of post-mitotic murine fibroblasts as a source of feeder cells markedly enhanced the survival and self-renewal of these epithelial cell subsets. In the absence of the feeder layer, once the primary cells had reached saturation density and were divided for further expansion, very few of them became adherent generating in general aborted colonies. These self-replicating epithelial cells showed expression of p63 (>70\% positive) (Fig. 1T) and nestin (not shown), CK-13/CK-10 (>60\% positive) (Fig. 1U), CK-19 (>90\% positive) (Fig. 1V) and were constantly CK-3 negative (Fig. 1W). Ki-67 were rare $(<2.5 \%$ positive) and PAS-positive goblet cells were never detected in these late cultures.

In addition, these cells expressed $C D 133$ mRNA, as detected by RT-PCR analysis (Fig. 1X). Negative controls included murine NIH.3T3 fibroblasts and primary cultured human corneal fibroblasts (the latter not shown).

These findings thus demonstrated a selected expansion of an enriched and rather homogeneous subset of conjunctival epithelial precursor cells with phenotypic characteristics of basal epithelial cells. Contamination of corneal epithelial elements was excluded by no expression of CK-3 by the conjunctival epithelial cells, in line with previous reports (Joseph et al., 2004, Papini et al., 2005). Probably in response to the culture conditions, all samples from different donors revealed that early in culture the most superficial levels sharply detached, including the positive CK-19 and less intensively positive CK13/CK-10 cells and goblet cells which were all released in the medium, while the inner basal and part of the parabasal cell compartment containing p63 and nestin positive cells remained stably anchored to the submucosa. At T2, the new epithelium appeared slightly different from the one observed at T0. It was probably generated from the basal and parabasal keratinocyte precursor cells that remained attached to the fragment at T1. These cells were rapidly adapting to the culture conditions entering into an active proliferative phase (judging by the increasing $\mathrm{Ki}-67$ staining and constantly low apoptotic cells), as reported in general in squamous epithelia maintained in similar cultures (Michelini et al., 2004; Papini et al., 2005). The basal precursor cells of the conjunctival epithelium kept for at least 2 weeks in culture within their natural environment, seem to have a less complex structure with simple patterns that generate a single phenotypic lineage and apparently have more autonomy with less dependence in extraepithelial influences for their pattering and survival. Consistent with previous observations (O'Connell et al., 2001), we detected no direct relation between $\mathrm{p} 63$ expression and cell cycle activity in cultured immature conjunctival basal epithelial cells.

Interestingly, conjunctival epithelial cells were able to migrate and line over the fragment's surface while maintaining their posi- 
TABLE 1

\section{ANTIBODIES USED, ANTIGEN DETECTION AND ANTIBODY SPECIFICITY}

\begin{tabular}{|c|c|c|c|c|c|c|}
\hline Antigen & Specificity & Species & Clone & Code & Source & References \\
\hline$\overline{C D 117}$ & Stem/progenitor cells & Rabbit & & A4502 & DakoCytomation & Vascotto et al., 2006 \\
\hline Nestin & $\begin{array}{l}\text { Mesenchymal and ocular } \\
\text { epithelial precursor cells }\end{array}$ & Mouse & $10 \mathrm{c} 2$ & SC-23927 & Santa Cruz Biotecnology & Borzanic et al., 2006 \\
\hline p63 & Epithelial progenitor cells & Mouse & $4 \mathrm{~A} 4$ & SC-8431 & Santa Cruz Biotecnology & Signoretti et al., 2000 \\
\hline MUC5AC & Goblet cells & Mouse & $45 \mathrm{M} 1$ & SC-21701 & Santa Cruz Biotecnology & Bara et al., 1991 \\
\hline Ki-67 & Proliferating cells & Mouse & MIB-1 & M7240 & DakoCytomation & Borre et al., 1998 \\
\hline CK-13/CK-10 & Conjunctival basal cells & Mouse & DE-K13 & M 7003 & DakoCytomation & Itakura et al., 1996; \\
\hline CK-19 & Conjunctival epibasal cells & Mouse & RCK108 & M-0888 & DakoCytomation & Stasiak et al., 1989 \\
\hline CK-3 & Corneal epithelium & Mouse & AE5 & CBL 218 & Cymbus & Papini et al., 2005 \\
\hline Vimentin & Endothelial and stromal cells & Mouse & VIM3B4 & M-7020 & DakoCytomation & Azumi and Battifora 1987 \\
\hline CD45 & Leukocytes & Mouse & 2B11 & M 0701 & DakoCytomation & Warnke et al., 1983 \\
\hline Pan-Cytokeratins & All epithelial cells & Mouse & $\mathrm{AE} 1 / \mathrm{AE} 3$ & M3515 & DakoCytomation & Tseng et al., 1982 \\
\hline
\end{tabular}

tion as a lining sheet of cells that differentiate and maintain tissue structure and function.

The presence of fibroblasts as feeder cells markedly enhanced the prolonged survival and self-renewal capacity of these cells, thus demonstrating the requirement of an exogenous suitable micro-environmental niche for epithelial conjunctival stem/precursor cells.

The conjunctiva normally contains in vivo all the components of the myeloid and tertiary lymphoid compartment, which are fundamental for immune defense of the ocular surface (Yamagami et al., 2005). In our present study, at T0 bloodderived monocyte/dendritic-like cells (judging from the morphology of $C D 45^{+}$cells) were present close to the basal lamina in the underlying stroma and infiltrating within the multilayered epithelium of the conjunctiva. At T1, when the upper epithelium detached, these cells were almost completely absent in the left epithelium, while their presence was still consistent in the underlying stroma. At T2, monocytes/dendritic-like cells were found again infiltrating the newly reconstituted epithelium, suggesting that their precursors had remained within the capillaries and maintained their capacity to migrate. The method offers important advantages, such as monitoring inducing factors or drugs affecting subpopulations of resident leukocytes within the conjunctiva, or determining how monocyte/dendritic-like cells can be induced to migrate and differentiate into the intraepithelial compartment.

\section{Experimental Procedures}

\section{Human conjunctival tissue}

Six human conjunctival explants were obtained from the Corneal Tissue and Cell Bank of Tuscany, Center "P. Perelli", Lucca, Italy. The tissue explants were maintained in EUSOL-C (Graft TEC, Alchimia Transplant s.r.I., Padova, Italy, cat. $\mathrm{N}^{\circ} \mathrm{REF}-10040$ ) for $2-4$ days at $4^{\circ} \mathrm{C}$ to avoid contamination before being processed.

\section{Cultures}

Tissue fragments and dispersed epithelial cells were maintained in EpiLife medium as described in Papini et al., 2005.

\section{$3 D$ - organotypic cultures on gelatin sponges}

The method was adapted from Chishima et al. (1997) with modifications (Papini et al., 2005).

\section{Isolation and expansion of epithelial basal stem/precursor cells in} co-culture with feeder NIH.3T3 fibroblasts

Prior to culture conjunctival fragments were treated as described in Papini et al., 2005.

\section{Histology and immunohistochemistry}

At each given pre-determined time interval (i.e. at T0, T1 and T2) of culture, tissue fragments were embedded in paraffin and sections $(<5 \mu \mathrm{m}$ of thickness) were stained with Gill's hematoxylin (Bio-optica, Milan, Italy,) and eosin (Eosin Y Sigma-Aldrich). PAS-staining was used for goblet detection (Pellegrini et al., 1999). Preliminary experiments performed using monoclonal antibody MUC5AC (Santa Cruz biotechnology, Santa Cruz, CA, U.S.A.) demonstrated the same targeting as the PAS reaction, as previously reported. Table 1 reports each antibody used, antigens detected, antibody specificity, antibodies's clones for monoclonal antibodies, source and references. Cells grown in monolayer on glass culture-chamber slides were first fixed for $6 \mathrm{~min}$ in absolute ethanol and then stained with antibodies. Immunohistochemistry was performed on sections using Dako Envision+TM System HRP (DakoCytomation, Carpinteria, CA, USA). Ki-67 (clone MIB-1) was revealed by polyclonal rabbit IgG conjugated with FITC (DakoCytomation). In order to measure cell apoptosis, tunel technology was performed by using In Situ Cell Death Detection Kit (Roche, Penzberg, Germany) and the detection of the DNA strand break was performed by fluorescent microscopy. Percentage of positive cells was evaluated after counting 500 cells in at least 3 different sections. All samples stained by immunofluorescence were counterstained by D.A.P.I. (Sigma-Aldrich).

\section{RT-PCR analysis for CD133 expression}

Total RNA was extracted from conjunctival epithelial cells according to the protocol of the manufacturer (QIAamp RNA Mini Kit, Qiagen GmbH, Hilden, Germany). Human cDNA CD133 (GenBank accession n AFO27208) was amplified (forward primers 5'CAGTCTGACCAGCGTGAAAA3' and reverse primers 5'TTCCATCCGGGTCTGTCCTAA3'), using Taq Platinum (Invitrogen, Merelbenke, Belgium). RT-PCR was performed following the protocol of the manufacturer (ImProm-II ${ }^{\mathrm{TM}}$ Reverse Transcription System, Promega Madison, WI, U.S.A.) obtaining a cDNA sequence of $181 \mathrm{bp}$.

\section{Acknowledgments}

Grant sponsors: Ministero Italiano dell'Università e Ricerca: P.F. "Stem 2001"; Ministero Italiano della Sanità (FIRB: P.S. on Quality of Life:"Post Genoma" and "New Organs"). Ministries of Foreign Affairs of Italy and the Czech Republic: Joint Scientific Project: KONTAKT. S.O.O.F.T. S.p.A., Italy; Foundation-ONLUS "Cellule Staminali e Vita", Pisa, Italy. 


\section{References}

AZUMI N. and BATTIFORA H. (1987). The distribution of vimentin and keratin in epithelial and nonepithelial neoplasms. A comprehensive immunohistochemical study on formalin- and alcohol-fixed tumors. Am. J. Clin. Pathol. 88:286-296.

BARA J., GAUTIER R., MOURADIAN P., DECAENS C. and DAHER N. (1991). Oncofetal mucin M1 epitope family: characterization and expression during colonic carcinogenesis. Int. J. Cancer 47: 304-310.

BORRE M., STAUSBOL-GRON B., NERSTROM B. and OVERGAARD J. (1998). Immunohistochemical BCL-2 and Ki-67 expression predict survival in prostate cancer patients followed expectantly. Prostate Cancer 5: 268-275.

BOZANIC D, BOCINA I. and SARAGA-BABIC M. (2006). Involvement of cytoskeletal proteins and growth factor receptors during development of the human eye. Anat. Embryol. 211: 367-77.

CHISHIMA T., YANG M., MIYAGI Y., LI L. and TAN Y. (1997). Baranov E, Shimada H, Moossa AR, Penman S, Hoffman RM. Governing step of metastasis visualized in vitro. Proc. Natl. Acad. Sci. USA 94: 11573-11576.

CONNON C.J., NAKAMURA T., QUANTOCK A.J. and KINOSHITA S. (2006). The persistence of transplanted amniotic membrane in corneal stroma. Am. J. Ophthalmol. 141: 190-192.

ITAKURA Y., SASANO F., DATE F., KATO K., SEKINE H., MORI S. and NATURA H. (1996). DNA ploidy, P53 expression and cellular proliferation in normal epithelium and squamous dysplasia of non-cancerous and cancerous human oesophagi. Anticancer. Res. 16: 201-208.

JOSEPH A., POWELL-RICHARDS A.O., SHANMUGANATHAN V.A. and DUA H.S. (2004). Epithelial cell characteristics of cultured human limbal explants. $\mathrm{Br}$. J. Ophthalmol. 88: 393-398.

LAVKER R.M., WEI Z.G. and SUN T.T. (1998). Phorbol ester preferentially stimulates mouse fornical conjunctival and limbal epithelial cells to proliferate in vivo. Invest. Ophthalmol. Vis. Sci. 39: 301-307.

MELLER D., PIRES R, T. and TSENG S.C. (2002) . Ex vivo preservation and expansion of human limbal epithelial stem cells on amniotic membrane cultures. Br.J.Ophthalmol. 86: 463-471.

MICHELINI M., ROSELLINI A., SIMONCINI T., PAPINI S. and REVOLTELLA R.P. (2004). A three-dimensional culture of the human exocervix for studying epithelial differentiation and migrating leukocytes. Differentiation 72: 1-12.

O'CONNELL J.T., MUTTER G.L., CVIKO A., NUCCIM., QUADE B.J., KOZAKEWICH H.P., NEFFEN E., SUN D., YANG A., MCKEON F.D. and CRUM C.P. (2001). Identification of a basal/reserve cell immunophenotype in benign and neoplastic endometrium: a study with the p53 homologue p63. Gynecol Oncol. 80: 30-36.

PALADINO G., MARINO C., LA TERRA MULE S., CIVIALE C., RUSCIANO D. and ENEA V. (2004). Cytokeratin expression in primary epithelial cell culture from bovine conjunctiva. Tissue Cell 36: 323-332

PAPINI S., ROSELLINI A., CAMPANI D., DEMATTEIS A., SELLI C. and REVOLTELLA R.P. (2004). Selective growth of epithelial basal cells from human prostate in a three-dimensional organ culture. Prostate 59: 383-392.
PAPINI S., ROSELLINI A., NARDI M., GIANNARINI C. and REVOLTELLA R.P. (2005). Selective growth and expansion of human corneal epithelial basal stem cells in a three-dimensional-organ culture. Differentiation 73: 61-68.

PELLEGRINI G., GOLISANO O., PATERNA P., LAMBIASE A., BONINI S., RAMA P. and DE LUCA M. (1999). Location and clonal analysis of stem cells and their differentiated progeny in the human ocular surface. J. Cell. Biol. 145: 769-782

PFLUGFELDER S.C., TSENG S.C., YOSHINO K., MONROY D., FELIX C. and REIS B.L. (1997). Correlation of goblet cell density and mucosal epithelia membrane mucin expression with rose bengal staining in patients with ocular irritation. Ophthalmology 104: 223-235.

POTTEN C.S. (1997). Stem cell. Academy Press, Harcourt Brace \& Co, London UK.

SANTOS M.S., GOMES J.A., HOFLING-LIMA A.L., RIZZO L.V., ROMANO A.C and BELFORT R. JR. (2005). Survival analysis of conjunctival limbal grafts and amniotic membrane transplantation in eyes with total limbal stem cell deficiency. Am. J. Ophthalmol. 140: 223-230.

SHATOS M.A., RIOS J.D., HORIKAWA Y., HODGES R:R:, CHANG E.L., BERNARDINO C.R., RUBIN P. A.D. and DARTT D.A., (2003) Isolation and characterization of conjunctival goblet cells. Inv.Ophthalmol.Vis.Sci. 44: 2477-2486.

SIGNORETTIS., MONTIRONI R., MANOLA J., ALTIMARI A., TAM C., BUBLEY G., BALK S., THOMAS G., KAPLAN I., HLATKY L., HAHNFELDT P., KANTOFF P. and LODA M. (2000). p63 is a prostate basal cell marker and is required for prostate development. Am. J. Pathol. 157: 1769-1775.

STASIAK P.C., PURKIS P.E., LEIGH I.M. and LANE E.B. (1989). Keratin 19: predicted amino acid sequence and broad tissue distribution suggest it evolved from keratinocyte keratins. J. Invest. Dermatol. 92: 707-716.

TSENG S.C., JARVINEN M.J., NELSON W.G., HUANG J.W., WOODCOCK MITCHELL J. and SUN T.T. (1982). Correlation of specific keratins with different types of epithelial differentiation: monoclonal antibody studies. Cel/30:361-72.

VASCOTTO S.G. and GRIFFITH M. (2006). Localization of candidate stem and progenitor cell markers within the human cornea, limbus and bulbar conjunctiva in vivo and in cell culture. Anat. Rec. A. Discov. Mol. Cell. Evol. Biol. 288: 921931.

WARNKE R.A., GATTER K.C., FALINI B., HILDRETH P., WOOLSTON R.E., PULFORD K., CORDELL J.L., COHEN B., DE WOLF-PEETERS C. and MASON D.Y. (1983). Diagnosis of human lymphoma with monoclonal antileukocyte antibodies. N. Engl. J. Med. 309: 1275-1281.

WEI Z.G., LIN T., SUN T.T. and LAVKER R.M. (1997). Clonal analysis of the in vivo differentiation potential of keratinocytes. Invest. Ophthalmol. Vis. Sci. 38: 753761.

YAMAGAMI S., YOKOO S., USUI T., YAMAGAMI H., AMANO S. and EBIHARA N (2005). Distinct populations of dendritic cells in the normal human donor corneal epithelium. Invest. Ophthalmol. Vis. Sci. 46: 4489-4494.

Published Online: 13th September 2007 


\section{Related, previously published Int. J. Dev. Biol. articles}

See our Special Issue Eye Development edited by Joram Piatigorski and Rob Grainger at: http://www.ijdb.ehu.es/web/contents.php?vol=48\&issue=8-9

Neural differentiation from human embryonic stem cells in a defined adherent culture condition Hossein Baharvand, Narges-Zare Mehrjardi, Maryam Hatami, Sahar Kiani, Mahendra Rao and Mahdi-Montazer Haghighi Int. J. Dev. Biol. (2007) 51: 371-378

Differentiation of human embryonic stem cells into hepatocytes in 2D and 3D culture systems in vitro Hossein Baharvand, Seyed M. Hashemi, Saeid Kazemi Ashtiani and Ali Farrokhi Int. J. Dev. Biol. (2006) 50: 645-652

\section{Plant stem cell niches}

Yvonne Stahl and Rüdiger Simon

Int. J. Dev. Biol. (2005) 49: 479-489

Ocular surface epithelial and stem cell development J. Mario Wolosin, Murat T. Budak and M.A. Murat Akinci Int. J. Dev. Biol. (2004) 48: 981-991

Polyembryony in parasitic wasps: evolution of a novel mode of development

Miodrag Grbic

Int. J. Dev. Biol. (2003) 47: 633-642

Quantitation of 3D ureteric branching morphogenesis in cultured embryonic mouse kidney

Luise A Cullen-McEwen, Gabriel Fricout, Ian S Harper, Dominique Jeulin and John F Bertram

Int. J. Dev. Biol. (2002) 46: 1049-1055

3D visualisation of cellular organisation during Arabidopsis meristem development

Jim Haseloff, Sarah Hodge, Smita Kurup, Laurent Laplaze, John Runions and Elisabeth Truernit

Int. J. Dev. Biol. (2001) 45: S27-S27

Morphogenesis of human tooth primordia: the importance of 3D computer-assisted reconstruction.

R J Radlanski

Int. J. Dev. Biol. (1995) 39: 249-256

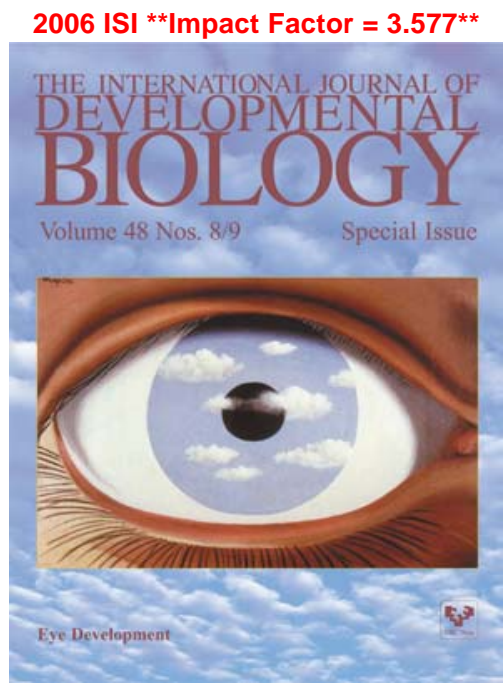

